\title{
The Effect of Pillar 1 on Efficient Investment Portfolio Choice in the Case of the United States
}

\author{
Krzysztof Ostaszewski ${ }^{\mathrm{a}, \mathrm{b}}$ \\ a Actuarial Program, Department of Mathematics, Illinois State University, Normal, IL 61790-4520, U.S.A. \\ ${ }^{\mathrm{b}}$ The Geneva Association, 53 route de Malagnou, Geneva 1208, Switzerland. \\ E-mail: krzysio@ilstu.edu
}

Pillar 1 of the U.S. retirement system is the Social Security system. It is both the largest social insurance system in the world and an important instrument of public policy. It provides universal retirement benefits based on wage history, and the number of years of service (up to 35 years). It is a core source of retirement income for American workers. In this paper, we consider this system as a part of capital markets, by asking how a person's optimal investment portfolio is affected by the existence of the Social Security System. We do this by calculating the optimal portfolio allocation at various levels of risk (i.e. the efficient frontier) for portfolios including a proxy for Social Security. This perspective is new in comparison to the existing literature on the subject. We show that the composition of the efficient frontier suggests arbitrage opportunities between Social Security and private capital markets, especially when portfolios optimal from the point of view of real returns are considered. We also note that exploitation of those opportunities may have important policy implications, as it may lead individual investors to treat Social Security as the "safe anchor" of their portfolio, and then taking more risk and assuming more leverage, in a potentially unsustainable fashion, in their remaining asset allocation.

The Geneva Papers (2013) 38, 675-700. doi:10.1057/gpp.2013.29

Keywords: Social Security; efficient frontier; arbitrage; retirement

Article submitted 14 January 2013; accepted 26 July 2013; published online October 2013

\section{Introduction}

Consumers who save for retirement place their savings in a portfolio of marketable assets, for example, stocks and bonds, or entrust them to financial intermediaries, such as banks, insurance companies or investment firms, who in turn locate them in portfolios of marketable capital assets, as well as loans and other private investment placements, which are less marketable, but very similar in their nature to marketable assets.

But marketable capital assets coexist with other non-marketable entities that provide future income streams. For example, acquisition of education is an investment in human capital, resulting in the creation of a future income stream. Another such entity that we consider in this paper is the acquisition of a future income stream in the form of Social Security benefits. Non-marketable rights to future pension benefits, usually related to wages, can be acquired in the United States within the private sector through defined benefit pension plans. But a much more widespread form of such acquisition is the system of social insurance: Old-Age, Survivors and Disability Insurance (OASDI), known commonly as Social Security, which is the Pillar 1 of the U.S. retirement system. Social Security is in fact a form of a defined benefit pension plan. In general, the price paid for a capital asset is the 
676

current consumption foregone in return for future consumption acquired. Although on the apparent monetary basis, funding for defined benefit pension plans and Social Security is obtained from group premiums paid; in economic reality, the individual worker pays for future benefits with foregone current consumption, that is, wages not received because of normal cost or payroll tax paid on his/her behalf. That consumption is foregone on an individual basis, just as payments are made when regular capital assets are purchased. In this paper we study the relationship of marketable capital assets obtained with direct monetary payments, to non-marketable Social Security benefit rights, obtained through indirect payment in the form of consumption foregone.

For the "shadow" capital assets held by Social Security participants purchased with foregone consumption and sold for benefits received, we will use the term Social Security Participation. We want to ask these questions:

- Can we measure, or at least approximate, the rate of return of Social Security Participation and, if so, how does it compare with returns of comparable marketable capital assets?

- What is the role of Social Security Participation in the composition of the personal investment portfolio? Consumers acquire such portfolios for their retirement needs in Pillar 3 of the retirement system.

- If there were significant discrepancies between the price (inferred from its rate of return) of Social Security Participation and marketable capital assets, what would be the effect on the composition of efficient portfolios, capital markets, the Social Security system or the national economy in general?

The debate over Social Security reform in the United States has included many arguments about the rate of return received by the system's participants. The 1994-1996 Advisory Council on Social Security ${ }^{1}$ scored reform plans according to their internal rate of return, the discounted benefit-to-tax ratio and the net present value. An alternative measure used often is a money's worth comparison of accumulated taxes paid vs present value of benefits received. ${ }^{2}$ In this paper, we diverge from all these approaches, in two respects:

- Previous studies assumed that benefits granted are paid regardless of the level of benefits, taxes or economic activity, and that taxes imposed are collected as pleased by the government authority.

- Previous studies have generally not analysed the Social Security system in reference to capital markets.

The premise that the social insurance system cannot deliver any amount of benefits it pleases and, in fact, the amount of benefits is dependent on the amount of taxes the system is able to collect is, of course, nothing new, but it has acquired new prominence in view of the funding problems of social insurance in general, and the debate over the privatisation of Social Security. Capital markets provide us with information about the market level of benefits paid for given contributions within the private sector. Although this relationship changes over time, it is quite clear that, historically, Social Security has redistributed wealth between generations (after consideration for the market level of returns on contributions).

\footnotetext{
${ }^{1}$ Social Security Administration (1997).

${ }^{2}$ Geanakoplos et al. (1999); Myers and Schobel (1992).
} 
This paper is not about that redistribution, but rather about projecting Social Security rates of return if the system could no longer redistribute between generations beyond the market levels, that is, if it could only deliver its steady-state rates of return. The reason why we separate the two is that political process determines redistribution, whereas the steady-state rates of return can reasonably be tied to the economy's long-term performance potential.

The perspective proposed here is mostly missing from the literature. Smetters and $\mathrm{Chen}^{3}$ have asked similar questions in their study, but their approach combined investment portfolio and Social Security in a life cycle utility-based approach (with constant relative risk aversion), using a predetermined parametrical model, fitted to empirical data (a similar model was used by Chai et $a l .^{4}$ in assessing the effects of the financial and economic crisis). Their results suggest that a progressive wage indexed social security system can fundamentally alter the optimal allocation between stocks and bonds over the life cycle. Richardson and Seligman ${ }^{5}$ analyse optimal portfolio allocation in the context of replacing the first pillar social security system by funded individual accounts. In this paper, instead of fitting investment portfolio into the economic model including Social Security, or contrasting Social Security with a funded system, we propose to bring Social Security into the investment world, and consider optimal asset allocation, including Social Security and capital assets, as an optimal investment portfolio problem.

\section{Pricing Social Security Participation}

In the seminal paper upon which the science of modern finance is founded, Markowitz ${ }^{6}$ pointed out that the pricing of capital assets is linked not only to rates of return earned by such assets, but also to the risk of the return. In standard economic analysis, the risk of a capital asset is a measure of uncertainty of utility of future consumption provided by that asset, and it is only the marginal utility of future consumption specifically provided by the said asset that matters. But in practice, it is common to settle for a much more simplified measure of risk: the standard deviation of the rate of return, as in the study by Markowitz. ${ }^{6}$

The capital asset pricing model (CAPM) ${ }^{7}$ added a new perspective to risk measurement. In the CAPM, only the systematic risk, and not the security specific risk, is the measure of risk, which affects the rate of return. The systematic risk is the overall market risk remaining after all the security-specific risk has been eliminated through diversification. In the CAPM, it is measured by security's beta, defined as the ratio of the covariance of that security's return with the return of the market to the variance of the return of the market. The rate of return is modelled as a random variable, whose expected value is a measure of return.

What can we say about the rate of return for Social Security participants? How it can be measured on the individual basis is somewhat problematic, because this social insurance system includes substantial insurance features. Risk pooling in insurance redistributes resources among the insured group and lowers the overall group rate of return because of

\footnotetext{
${ }^{3}$ Smetters and Chen (2010).

${ }^{4}$ Chai et al. (2011).

${ }^{5}$ Richardson and Seligman (2005).

${ }^{6}$ Markowitz (1952).

7 Treynor (1962); Sharpe (1964); Lintner (1965); Mossin (1966).
} 
678

having to pay for administration of insurance. The rate of return is more meaningful for the whole group. We simplify the model by only considering the Old Age and Survivors (OASI) portion of the Social Security system, that is, disability benefits and their financing are excluded, and we only consider the retirement system including survivors' benefits. In the model considered, participants make contributions through their own and their employers' payroll taxes, and receive benefits in the form of old-age pensions or survivors' benefits. The approach is justified by two reasons: the Social Security Disability Income programme collects its own taxes, and runs its own separate trust fund, and the OASI portion of the system closely resembles the private retirement market, where investors achieve analogous objectives via purchases and sales of market instruments. The entire Social Security system collects payroll taxes and distributes benefits. One could therefore view the function of the social insurance system as a restructuring of payroll taxes into payments to beneficiaries. This is quite similar to a derivative security structure where cash flows of the underlying security (commonly called the underlying in investment terminology) determine the payments to derivatives holders. The analogy is direct for individual participants, whose benefits payments are "carved out" from payroll tax collections based on their benefit formula. For all participants in aggregate, payroll tax collections flow through to aggregative benefits. This is the reason why we consider payroll tax collections as the proxy for aggregate Social Security Participation. Therefore, in this paper, the rate of return on the Social Security Participation in the aggregate is represented by the growth rate of payroll taxes.

Samuelson ${ }^{8}$ analysed the steady-state relationship between present and future consumption in relation to the rate of growth of the economy. Samuelson's analysis implies that the natural rate of return within a social insurance retirement system is the overall rate of growth of payroll tax receipts. Let us try to explain this reasoning within the simplest context of a stable population. Social insurance is designed as a pay-as-you-go system, which in its steady state pays out all its receipts in benefits. Assume that a stable population has a natural growth rate of $r$, with constant wages and all workers working from age 25 and retiring at age 65 . Let the payroll tax rate be set at a constant amount $\pi$, and the Social Security system be designed to function on a pay-as-you-go basis, with each beneficiary receiving a unit benefit continuously from age 65 to death. Then the payroll tax premium ${ }^{9}$ is:

$$
\pi=\frac{\int_{65}^{\omega} e^{-r x} l_{x} \mathrm{~d} x}{\int_{25}^{65} e^{-r x} l_{x} \mathrm{~d} x},
$$

where $\omega$ is the limiting age, and $l_{x}$ is the size of the population aged $x$. On the other hand, if instead of pay-as-you-go, the system was funded with marketable securities having earned exactly the rate $\delta$, then the continuous annual premium that pays for a unit benefit paid continuously for life starting at age 65 is:

$$
\pi=\frac{\int_{65}^{\omega} e^{-\delta x} l_{x} \mathrm{~d} x}{\int_{25}^{65} e^{-\delta x} l_{x} \mathrm{~d} x} .
$$

And since these are the same payments and benefits, the rate of return for a pay-as-you-go participant is exactly the rate $\delta$ earned by the marketable alternative, which must equal the

\footnotetext{
${ }^{8}$ Samuelson (1958).

${ }^{9}$ Keyfitz and Beekman (1984), Chapter 3.
} 
rate of growth $r$. As Keyfitz and Beekman ${ }^{9}$ comment, this simple observation generalises naturally to a situation where the population is replaced by the taxable payroll, and growth observed is calculated on an after-inflation basis, so that the continuous life-annuity paid in benefit is a real annuity, constant after inflation adjustment. This, of course, assumes a constant payroll tax rate. Thus, the rate of growth of the payroll tax collected becomes the rate of return.

Admittedly, Social Security Participation is not a marketable security, and its payments are, for current workers, deferred into the very distant future. Furthermore, participants do not have any choice about the purchase, and cannot directly trade their benefits. What this perspective misses is that, while Social Security Participation may not "move" in price towards other capital assets, other capital assets can, and most likely will, move in response to statutory pricing of Social Security Participation. The arbitrage pricing theory ${ }^{10}$ tells us if a security not traded in the market can be replicated by securities traded whose prices are available, then the untraded security's price will be determined by such replication. The dynamics between Social Security Participation and its private financial assets are somewhat similar to the relationship that the Federal Reserve's monetary policy (or any central bank's monetary policy) has with the bond market in dealing with interest rates, or the Federal Reserve and the Treasury have with the foreign exchange markets in dealing with foreign currencies rates of exchange for the U.S. dollar. While "hard", direct, arbitrage is not always possible in interest rates or foreign exchange, Krugman ${ }^{11}$ showed the relationship of government foreign exchange targets to market dynamics, and Cook and Hahn ${ }^{12}$ studied similar dynamics for the interest rates markets. Farnsworth and Bass ${ }^{13}$ show that arbitrage-type reasoning can be in fact applied to interest rates markets in the presence of the official policy targets set by the central bank. The situation of Social Security Participation vis-à-vis marketable capital assets is quite similar, given publicly-stated payroll tax rates and benefit formulas.

How can arbitrage be performed in the case of Social Security Participation? The simplest argument goes as follows. If Social Security Participation is cheap, that is, it grants large benefits in relation to the payroll taxes paid, other capital assets are relatively expensive and will be sold until the relationship between the statutory asset, Social Security Participation and the market assets is more reasonable. With full arbitrage, one would expect participants to purchase more Social Security Participation. This is not always possible, but can be partially achieved by investing in the growth of one's future wages, that is, education. This is, in fact, exactly the argument advanced by Mueller, ${ }^{14}$ who claims that the U.S. Social Security System has contributed to productivity growth by creating incentives for investment in education. There is, however, a limit to indirect Social Security Participation purchases through education, and any greater degree of arbitrage can only be attained by selling capital assets and consuming more (although one could argue that excessive consumption could be a form of investment in human capital: after all, a happy worker may be a more productive worker). On the other hand, if the social insurance system grants benefits which are too small

\footnotetext{
${ }^{10}$ Ross (1976); see also Panjer (1998).

${ }^{11}$ Krugman (1991).

12 Cook and Hahn (1989).

${ }^{13}$ Farnsworth and Bass (2003).

${ }^{14}$ Mueller (1997, 1999).
} 
680

in relation to the payroll taxes paid (this has not been, historically, the case in the United States, but many underdeveloped or former communist economies provide examples of such a situation), there are two ways to arbitrage against the government: avoid paying the payroll tax and increase investments in marketable assets with relatively lower prices, for example, foreign capital assets.

The study of the relationship between prices of capital assets and the price of Social Security Participation is definitely a complex one. In addition to the redistribution between age cohorts (which, at the market rate of return, performs exactly the same function as the capital markets, and, beyond the market level of rates of return, is probably unsustainable), social insurance has intra-cohort redistribution mechanisms which are significantly more difficult to arbitrage against. On the other hand, other government activities, such as taxation of investment income and government income support programmes for the poor also affect capital markets in a similar manner. However, excessive arbitrage opportunities created by statutory pricing of Social Security may cause significant economic and social dislocations, by sending false signals about the relationship of marginal utilities of work and leisure.

We do not have an easy direct way to compare capital assets and Social Security Participation, and this is not just because the latter is not marketable. There is also the issue of risk. While Social Security Participation enjoys a federal government guarantee of payment comparable with that of the U.S. debt, in the long run, it can undergo fluctuations in value, due to fluctuations in wages and productivity levels, demographics, the economy's ability to carry the payroll tax burden and political influences. When we compare it with other assets, we should not only seek some proxy for Social Security Participation's rate of return, but also account for its risk relative to other securities. In this paper, we propose the rate of growth of taxes collected for the OASI trust fund (excluding the Disability Income fund) as the proxy for the rate of return on Social Security Participation, with its volatility as the measure of risk. This is, we agree, an imperfect proxy, but it is supported by the arguments stated above. This proxy is derived as a long-term rate of return to cohorts only. Such a model is very similar to using a stock market index or a bond market index, instead of individual stocks or bonds, for camparing asset classes. After all, not all investment portfolios are invested in a stock or bond market index, yet it is quite common to use such indices for comparison of portfolios. Thus our approach is not significantly more restrictive than commonly used models of capital assets portfolios. Also, annual rates of growth of payroll taxes are time dependent and, ideally, one should use a time-series approach to analyse them. Again, this argument applies equally to rates of return of the Standard and Poor's 500 Index, also a time series, and not a random sample from a probability distribution, yet the standard form of Markowitz's modern portfolio theory does treat market returns this way in standard applications.

We believe that our model, while imperfect, does catch the essence of the inter-cohort exchange. Also, it can be calculated and can be compared with statistics available for marketable securities which perform the same inter-cohort exchange function. Although a perfect design for arbitrage between Social Security and capital markets can't be determined based on this proxy, we propose a comparison based on the contribution of the Social Security Participation in an efficient portfolio of an American investor, based on historical data, and we believe that our conclusions suggest that such arbitrage may indeed have been taking place. One could also argue that, demographically, the future may not be like the past, because of the "baby boom" generation, and this would make using historical 
estimates debatable for the prospective portfolio. But these demographic phenomena will affect both Social Security and capital markets, and to the degree that one treats Social Security Participation as a security, it is reasonable that its relationship with other capital assets will be preserved through changing demographic changes.

In our analysis, we effectively replace the great variety of individual circumstances of Social Security participants, and their individual wage and benefit histories and expectations, by one random variable expressing their rate of return. This is an approach similar to models based on a representative agent model. Such models are described in detail by Huang and Litzenberger, ${ }^{15}$ and outlined in Section 4.4 of Panjer. ${ }^{16}$ They require that the following assumptions be met:

- all agents in the economy have homogeneous beliefs;

- agents have time-additive, state-independent, utility functions that are increasing, concave and differentiable;

- the securities market is complete.

Furthermore, utility-based equilibrium models of capital markets assume that the markets have the aggregation property, that is, the state prices observed do not depend on the initial wealth of the agents. Under these assumptions, all market properties can be analysed in terms of a representative individual agent's utility function.

These idealised assumptions are not true for either Social Security or for existing capital markets. Nevertheless, we propose that just as analysis of idealised capital markets alone can provide us with valuable insights, so can our analysis of idealised capital markets combined with Social Security Participation. Most importantly, all assumptions we use here with respect to Social Security are equally objectionable when applied to capital markets (e.g. individual investors do not really receive market index returns, do pay taxes, do face friction in trading, etc.), yet it is a widely accepted practice to analyse capital markets returns in the same manner as this paper proposes.

The rate of return earned by the pay-as-you-go social insurance participants is a central issue in many debates related to reform or privatisation of existing systems, including the U.S. Social Security system. Proponents of privatisation argue that if the existing social insurance is replaced with private accounts invested in marketable securities, such private accounts will earn a higher rate of return. ${ }^{17}$ The rates of return could be as high as 7 per cent real (historical equity returns, see Ibbotson Associates ${ }^{18}$ ) vs projections of 2 per cent real (or less) for the Social Security system's current participants. ${ }^{19}$

On the other hand, Mueller ${ }^{14}$ argues that the historical real (after inflation) rate of return on Social Security contributions was approximately 8 per cent and that there is no reason to expect different returns in the future. This stands in sharp contrast with Leimer's ${ }^{19}$ estimates. Indeed, a rough estimate based on Samuelson's insight, and Keyfitz's and Beekman's calculation, points to future rates of return in the range of about 1.5 per cent population growth plus about 2 per cent productivity growth, for a total growth rate of taxable payroll of

\footnotetext{
15 Huang and Litzenberger (1988).

16 Panjer (1998).

${ }^{17}$ Palacios and Whitehouse (1998); Timmins (1998).

${ }^{18}$ Ibbotson Associates (2011).

${ }^{19}$ Leimer (1994).
} 
682

about 3.5 per cent at most (with a possible negative adjustment of about -1.5 per cent for intergenerational redistribution, as pointed out by Geanakoplos et al. ${ }^{20}$ ).

Many of the actual calculations for Social Security data have been performed not for the rate of return, but for historical money's worth analysis for system participants or internal rate of return. Report of the 1994-1996 Advisory Council on Social Security is a key example of this methodology. In its analysis, the report scored three main reform plans according to their internal rate of returns, the discounted benefit-to-tax ratio and the net present value. Geanakoplos et ll $^{21}$, or Myers and Schobel, ${ }^{22}$ used similar measures. Although we believe that these existing analyses are important contributions to the public policy debate, they are retrospective and ignore the risk dimension. Thus, they are not applicable to the individual investor's decision-making process. We believe that the prospective procedure of this paper, in the portfolio context, is more aligned with the process of choosing one's investment portfolio, and it provides a realistic assessment of returns available in the future. Also, past returns estimates ${ }^{14}$ include returns due to tax increases, and subsequent granting of additional benefits. Those are unlikely to continue in the future. Long-term returns must come from the growth of the economy and the resulting growth of wages, not from tax increases. An individual, or even a group, can indeed win in the political lottery and receive benefits extracted from others, but we cannot rationally assume this to be a permanent source of income for everyone.

What is the reality of rates of return to Social Security Participation and what are the exact sources of those returns? How does the Social Security Participation compare with marketable securities? We will attempt to answer this question in more detail now, in a way that incorporates both returns and risks of Social Security, in a portfolio context.

\section{Risk and return of social security participation}

Both that individual's special circumstances and the system's redistribution features can affect the rate of return enjoyed by an individual social insurance participant. For example, the benefit formula in Social Security is intended to favour low-income participants, but counting only 35 years of wage history favours high-income participants (whose higher incomes are generally related to longer education, thus shorter career duration, but with higher wages). On the other hand, rates of return to generational cohorts are naturally determined by the growth rate of taxable payroll. There is, however, a way to change this balance. The system may redistribute income not only within a generation, but also between generations, beyond the redistribution (or, actually, relative pricing of current consumption in terms of future uncertain consumption) achieved by the equilibrium of capital markets. For example, the U.S. Social Security system has paid benefits to early generations of beneficiaries without collecting taxes from most of them, or collecting very little. This has caused those beneficiaries to enjoy very high rates of return, well beyond the market rates they could have earned. Furthermore, if the tax rates of the system are increased and benefits are increased accordingly, participants who previously paid lower payroll tax rates and now

${ }^{20}$ Geanakoplos et al. (1998).

${ }^{21}$ Geanakoplos et al. (1999).

${ }^{22}$ Myers and Schobel (1992). 
enjoy increased benefits also experience higher rates of return. One more method of increasing rates of return is to increase workforce coverage. This way workers previously covered, who were then a part of a smaller system, can enjoy higher benefits due to greater tax collections from wider workforce coverage now. The third way to artificially increase payroll tax growth is to increase the portion of wages covered by payroll taxes (in the United States, only $\$ 3,000$ of annual wages were covered by payroll taxes until 1950 , while as of 2008 , the first $\$ 102,000$ of annual income is subject to payroll taxes). All these features increase rates of return to past generational cohorts. We will attempt to make appropriate adjustments in the growth rate of payroll taxes for these three factors: tax rate increase, coverage increase and contribution base increase.

What is the experience in that rate of growth of payroll taxes in the United States? The annual reports of the Board of Trustees of OASDI and the Social Security Administration's website provide information about the amount of income of the trust fund throughout the history of the system, annually, as well as information about historical and current tax rates and workers coverage. Intrinsically, adjusted for the growth in coverage and tax rates, growth rate $g$ of the payroll tax receipts can be estimated from these data as

$$
g=\frac{1+g_{H}}{\left(1+g_{C}\right)\left(1+g_{T}\right)\left(1+g_{W}\right)}-1,
$$

where $g_{H}$ is the actual growth rate of payroll tax receipts, $g_{C}$ is the growth rate of coverage, $g_{T}$ is the growth rate of the tax rate, and $g_{W}$ is the growth rate of portion of wages taxed (we use the ratio of maximum contribution base to national average wage index, as calculated by the Office of the Actuary of Social Security Administration). This natural rate of return of Social Security Participation can be appropriately compared with rates of return of other securities. The purpose of such a comparison is to attempt to create an efficient portfolio incorporating Social Security Participation, prospectively. We will look at the Social Security Participation in relation to key indices of U.S. capital markets, as published by Ibbotson Associates ${ }^{18}$ :

Large capitalisation U.S. stocks (Standard and Poor's 500 Index serves as proxy),

Small capitalisation U.S. stocks,

Long-term corporate bonds,

Long-term U.S. Treasury bonds,

Intermediate-term U.S. Treasury bonds, and

U.S. Treasury bills.

We also consider real (i.e. after inflation) returns of all these assets. Appendix A presents the data on rates of return of Social Security Participation (as adjusted in (1)) and the asset classes listed, while Appendix B presents analogous data on real returns of all of them. The returns are available for the years 1938-2010. Figure 1 shows the nominal returns from Social Security Participation (after adjustment for tax increases), and Figure 2 shows the real rates of return from Social Security Participation (again after tax increases adjustment).

The data show extreme variability in the first several years of the functioning of Social Security. The first four data points for nominal returns are: $-53.48,54.38,-40.48$ and 125.62 per cent. In the years 1942-2010, no data points are even close to the ranges of these first four data points. The four points are all more than two standard deviations from the data mean. In view of that, we exclude these four points from consideration as outliers. 


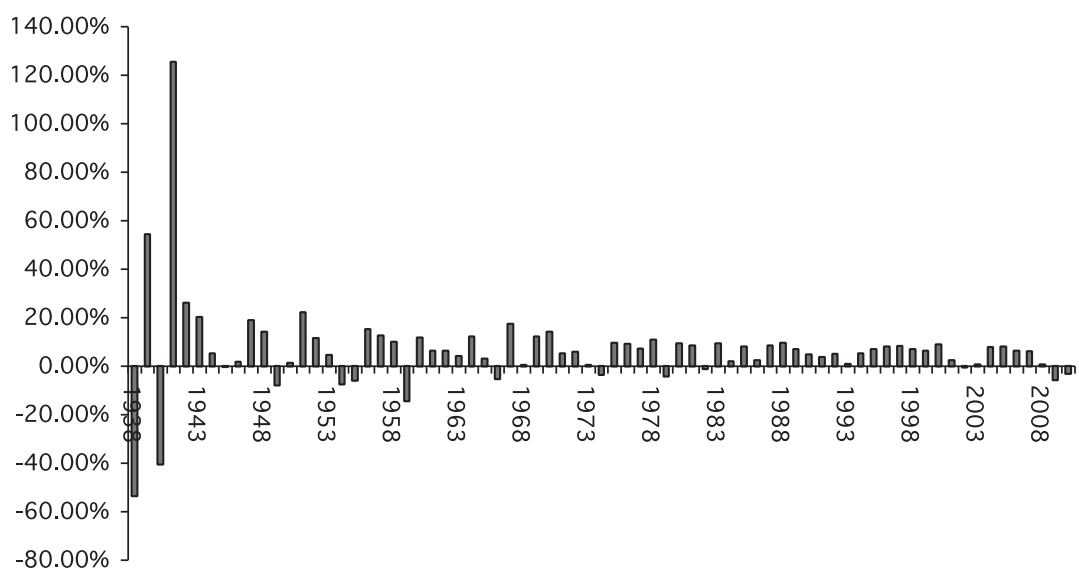

Figure 1. Historical nominal rates of return of Social Security Participation, 1938-2010.

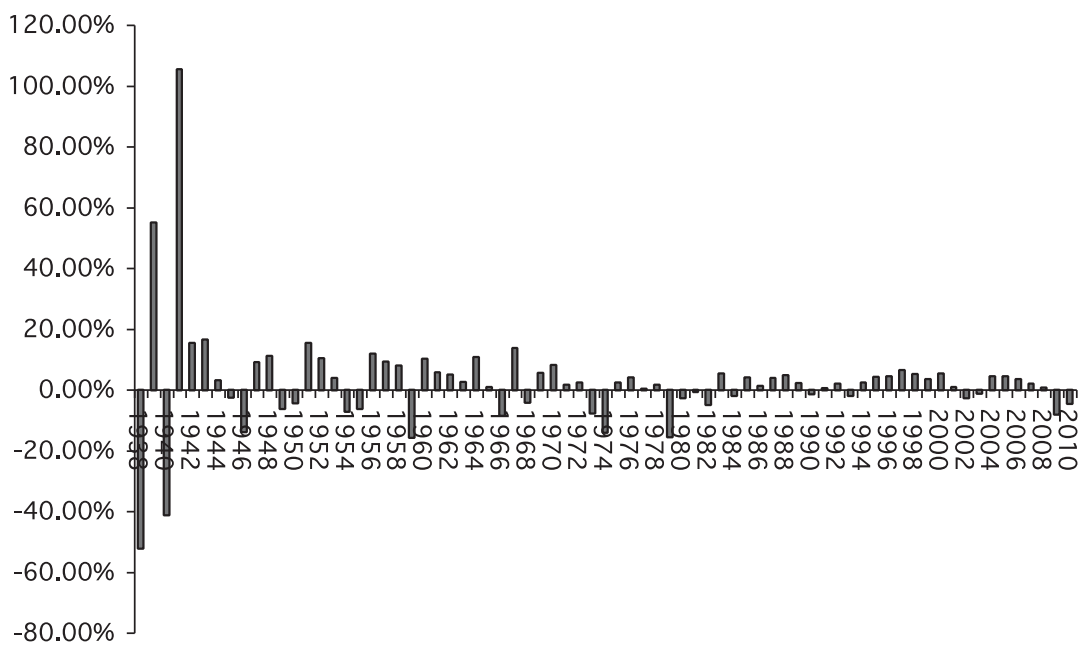

Figure 2. Historical real rates of return on Social Security Participation, 1938-2010.

With adjustments from (1) we calculate that Social Security Participation has an arithmetic average annual return of 5.84 per cent, with a standard deviation of 7.23 per cent. The actual earned rate of return, that is, geometric average, was approximately 5.59 per cent. These are nominal rates. The real return arithmetic average was 1.86 per cent, with a standard deviation of 7.04 per cent, and the actual compound annual return (geometric average) was 1.6135 per cent. Let us note that the real return was calculated based on nominal rates of return for a given year and the inflation rate (Consumer Price Index for Urban Consumers, unadjusted) for the same year. We summarise information about historical rates of return in Figures 1 and 2, and Tables 1 and 2. The value of 1.86 per cent may actually be an 
Table 1 Summary statistics of nominal rates of return, 1942-2010

\begin{tabular}{lccc}
\hline & $\begin{array}{c}\text { Mean } \\
\text { return (\%) }\end{array}$ & $\begin{array}{c}\text { Standard } \\
\text { deviation (\%) }\end{array}$ & $\begin{array}{c}\text { Correlation w/ } \\
\text { Social Security }\end{array}$ \\
\hline Social Security Participation & 5.84 & 7.23 & 1.0000 \\
Large capitalisation stocks & 12.95 & 17.36 & 0.0477 \\
Small capitalisation stocks & 18.87 & 26.76 & 0.0739 \\
Corporate bonds & 6.26 & 9.04 & -0.0952 \\
Long-term Treasury bonds & 6.12 & 10.30 & -0.1110 \\
Intermediate-term Treasury bond & 5.71 & 6.04 & -0.0588 \\
Treasury bills & 4.18 & 3.09 & -0.0239 \\
\hline
\end{tabular}

Table 2 Summary statistics of real rates of return, 1942-2010

\begin{tabular}{lccc}
\hline & $\begin{array}{c}\text { Mean } \\
\text { return (\%) }\end{array}$ & $\begin{array}{c}\text { Standard } \\
\text { deviation (\%) }\end{array}$ & $\begin{array}{c}\text { Correlation w/ } \\
\text { Social Security }\end{array}$ \\
\hline Social Security Participation & 1.86 & 7.04 & 1.0000 \\
Large capitalisation stocks & 8.86 & 17.74 & 0.1660 \\
Small capitalisation stocks & 14.54 & 26.39 & 0.1476 \\
Corporate bonds & 2.36 & 9.84 & 0.0804 \\
Long-term Treasury bonds & 2.23 & 11.04 & 0.0556 \\
Intermediate-term Treasury bond & 1.78 & 6.74 & 0.0883 \\
Treasury bills & 0.27 & 3.28 & 0.0743 \\
\hline
\end{tabular}

over-estimate. Figure 3 shows the evolution of arithmetic averages for a 39-year period ending in years ranging from 1980 until 2010, and we see that the averages are declining, ending with the lowest two values of 0.59 and 0.43 per cent.

On a nominal basis, Social Security Participation has a positive correlation with stocks and a negative correlation with bonds. Thus, Social Security Participation provides diversification benefits for bond portfolios, while having less diversification potential with equities (but some benefits do exist, as only perfectly correlated securities do not provide such benefits).

The correlations of Social Security to stocks and bonds provide an interesting perspective on the debate over the Social Security trust fund investments. The existing trust fund places any excess funds in special issue long-term U.S. government bonds. In order to resolve the long-term funding shortfall of the system, it has been proposed to invest some portion of the trust fund in equities. Our analysis indicates that investing trust fund in bonds lowers the overall risk of the system, because of generally negative correlation with bonds, while investing it in equities would offer less of such a benefit.

The existence of diversification benefits of Social Security when combined with bonds is obvious. But even just in combination with stocks we can establish them formally, using the methodology proposed by MacMinn. ${ }^{23}$ When two assets exhibit positive correlation, the condition for positive diversification (i.e. diversification providing more efficient portfolios than either of the assets themselves, with positive allocation to either asset), as developed by MacMinn $^{23}$ is $\left(\rho \sigma_{1} / \sigma_{2}\right)<\left(\mu_{1} / \mu_{2}\right)<\left(\sigma_{1} / \rho \sigma_{2}\right)$, where $\mu_{1}$ and $\sigma_{1}$ are the expected return and

\footnotetext{
23 MacMinn (1984).
} 


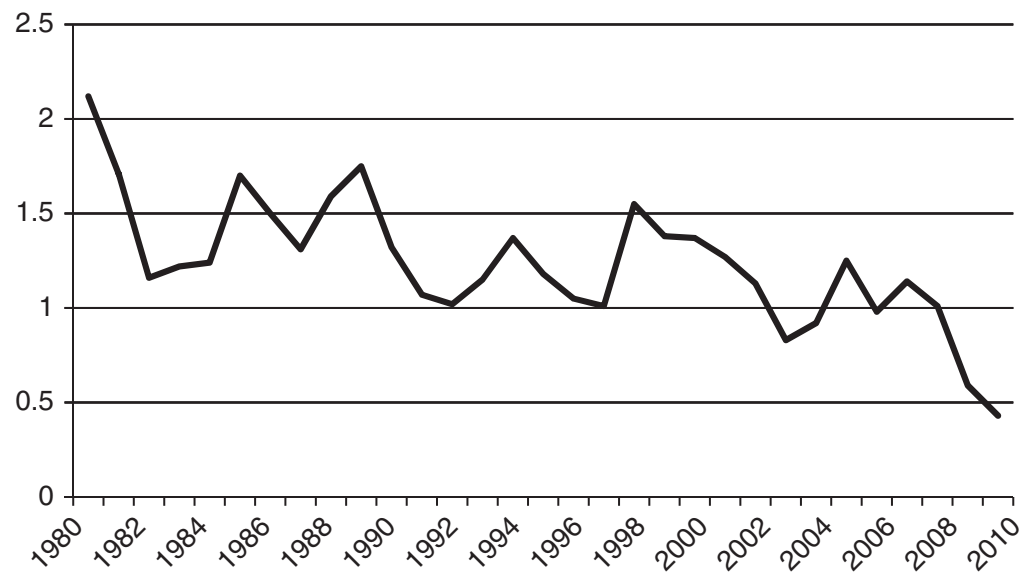

Figure 3. Rolling averages of Social Security Participation real rates of return for 39-year periods ending in the year given on the horizontal axis.

standard deviation of the rate of return for the first asset, $\mu_{2}$ and $\sigma_{2}$ are the analogous quantities for the second asset, and $\rho$ is the correlation coefficient for their rates of return. In the case of Social Security (treated as asset No. 1) and large capitalisation stocks (treated as asset No. 2), we have: $\mu_{1}=0.0584, \sigma_{1}=0.0723, \mu_{2}=0.1295, \sigma_{2}=0.1736$ and $\rho=0.0477$. Substituting these values into the above condition derived by MacMinn, ${ }^{23}$ we obtain:

$$
\frac{0.0477 \cdot 0.0723}{0.1736} \approx 0.0198<\frac{0.0584}{0.1295} \approx 0.4509<\frac{0.0723}{0.0477 \cdot 0.1736} \approx 8.7339
$$

for nominal returns. Therefore, for nominal rates of return, combining large stocks with Social Security does provide diversification benefits. For real rates of return, we have: $\mu_{1}=0.0186, \sigma_{1}=0.0704, \mu_{2}=0.0886, \sigma_{2}=0.1774$ and $\rho=0.1660$. Substituting these values into the MacMinn's condition, we get:

$$
\frac{0.1660 \cdot 0.0723}{0.1736} \approx 0.0659<\frac{0.0186}{0.0886} \approx 0.2099<\frac{0.0723}{0.1660 \cdot 0.1736} \approx 2.3908,
$$

and the positive diversification condition is again confirmed.

Before we proceed to the efficient frontier, let us note one more context of analysis. One might ask whether we should also study Social Security Participation from the perspective of the CAPM. In the CAPM, the measure of risk is beta. The CAPM states that under a set of simplifying assumptions, the random rate of return of a security $r$ is related to the risk-free rate of return $r_{F}$ and the market (meaning the market of all risky assets) random rate of return via the following formula ${ }^{24}$ :

$$
E(r)-r_{F}=\beta\left(E\left(r_{M}\right)-r_{F}\right)
$$

In this expression, beta $(\beta)$ is the covariance of returns of the security to the returns of the market, divided by the variance of market returns. We will estimate beta of Social Security

\footnotetext{
${ }^{24}$ Lintner (1965); Mossin (1966); Sharpe (1964); Treynor (1962).
} 
Participation by taking returns of large capitalisation stocks (S\&P 500) for market proxy. The CAPM formula suggests linear regression of excess returns (excess over the risk-free rate) as a method of beta estimation. For the 1942-2010 data we get these regression results:

Regression $F$-statistic $=1.3578, p$-value 0.2481 , not statistically significant,

Intercept $(\alpha)=0.0111, p$-value 0.3015 , not statistically significant,

Beta $(\beta)=0.0626, p$-value 0.2482 , not statistically significant,

95 per cent confidence interval for beta $=(-0.0446,0.1698)$.

We must stress that the regression is performed without any consideration for the temporal nature of the data. Of course, this is standard in finance literature on the subject. The results are not statistically significant. This is not surprising: one of the key assumptions of the CAPM is that all assets are marketable, and Social Security is not. The CAPM-based analysis does not appear to be a promising avenue for studying Social Security.

In the next section we will analyse the most effective asset allocation to U.S. asset classes, if Social Security is included as an alternative asset class. We do use an imperfect aggregate proxy for Social Security in the context of an individual portfolio. The point of this analysis is that individual investors are affected by potential arbitrage opportunities between Social Security and capital markets, and adjust their market portfolios accordingly. We seek to determine how investors change in response to Social Security. Of course, the indices representing capital assets classes' performances are also imperfect aggregate proxies, as no real person has only these idealised choices in the individual asset allocation decision.

We perform our analysis for both nominal returns and real (i.e. after inflation) returns. Although the analysis for real returns is more meaningful economically, in our view nominal-returns-optimal portfolios should also be considered, due to imperfections of inflation measures, and limited availability of inflation hedges for retail investors (e.g. while gold and real estate have been traditionally viewed as inflation hedges, recent volatility of these has challenged this traditional perspective).

\section{Efficient frontier analysis}

Markowitz ${ }^{6}$ defined the efficient frontier as the set of those investment portfolios, which offer the highest level of expected return for a given level of standard deviation of returns. This is typically stated as: the set of portfolios with the highest expected return for a given level of volatility. Markowitz's study initiated modern finance theory, which has eventually resulted in the creation of the CAPM and the arbitrage pricing theory.

In this paper, we create the efficient frontier for an investor who, in addition to standard asset classes, ${ }^{18}$ includes Social Security Participation in his/her portfolio. Based on the historical returns of asset classes (given in the appendices), we estimate expected returns, standard deviations of returns and correlations of returns, and then calculate the efficient frontier for U.S. investors. The optimisation was done using the Solver add-in application in Excel. The calculation is entirely data-driven; we do not assume any specific investor utility, or other form or preferences. In a repeated step-wise calculation, automated with an Excel macro, the optimal portfolio is calculated for each level of expected return.

The efficient frontier can be calculated either assuming both long and short (i.e. positive and negative) positions in asset classes, or just long positions (i.e. disallowing negative 
allocations). We performed our analyses using both assumptions, for nominal and real returns, for annual data for the period 1942-2010. We began by assuming no adjustment for tax rate growth, coverage increases, and compensation base (i.e. taking raw growth rates for trust fund income). This analysis, while providing no insight about projected rates of return, does help understand the perception of Social Security by past and current participants, who have experienced historical returns including the benefits (to them) of raising taxes. The result is shown in Figure 4. Note that Figure 4 shows both the efficient frontier, that is, best expected return for each level of portfolio return standard deviation (volatility), and the efficient portfolio allocation to Social Security for each level of volatility. The two dependent variables use the same scale. We see that, from the perspective of a historical Social Security participant, the system has been a strong addition to a portfolio, with optimal allocation exceeding half of the portfolio for standard deviations ranging from approximately 7.5 to 15 per cent. But the past returns used in this analysis may not be indicative of future returns, because in the past, the system has experienced substantial increases in the tax rate and the fraction of workers paying those taxes. Since the last major reform of Social Security (the 1983 Social Security Amendments), no such increases have occurred and, in fact, there was a temporary cut in the tax rate in the period 2011-2012.

Prospectively, optimal allocation must consider the fact that future payroll tax increases, similar to historical ones, are unlikely. The efficient frontier with Social Security return adjusted for tax increases (as described in Eq. (1)) is given in Figure 5. We see a substantial portfolio allocation to Social Security Participation, but at a much lower level. If we allow short sales, we obtain the efficient frontier presented in Figure 6. We see in Figures 5 and 6 that using realistic projected returns for Social Security, we arrive at significantly lower efficient portfolio allocations (i.e. portion of an optimal portfolio, which should be invested in Social Security), and if short sales are allowed, an optimal portfolio involves a large short position in Social Security.

We observe that optimal asset allocation to Social Security Participation changes significantly when short sales are allowed. This allocation actually increases with risk tolerance. It is also interesting to note the following structure of optimal portfolios for

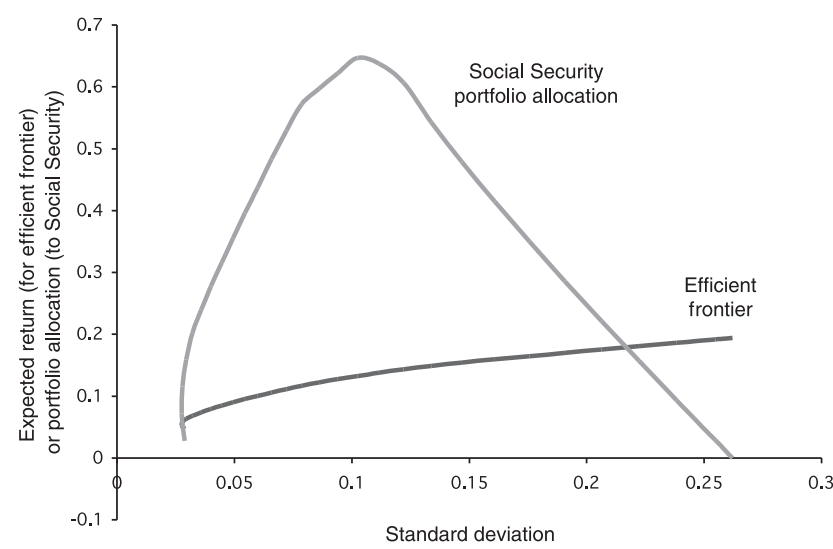

Figure 4. Efficient frontier of U.S. asset classes, including unadjusted Social Security, and allocation to Social Security Participation. No short sales allowed. 


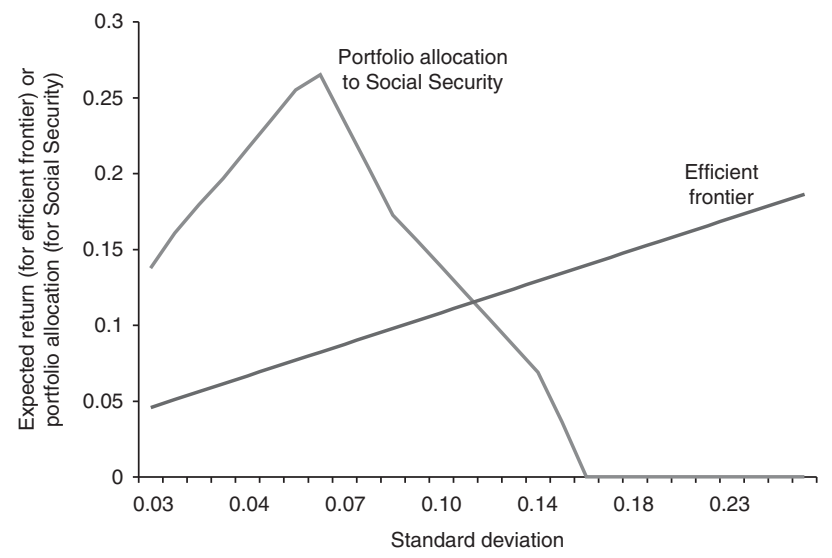

Figure 5. 1942-2010 efficient frontier of U.S. asset classes, Social Security (adjusted), and allocation to Social Security Participation. No short sales allowed.

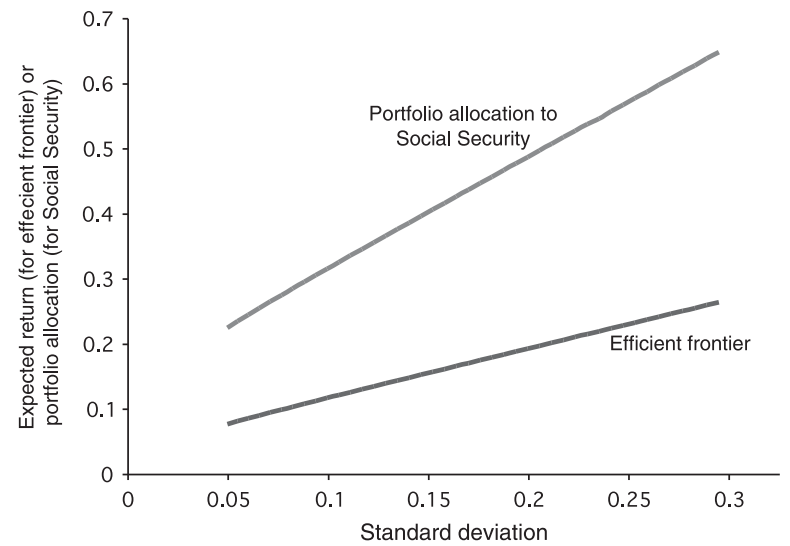

Figure 6. 1942-2010 efficient frontier of U.S. asset classes, Social Security (adjusted), and allocation to Social Security Participation. Short sales allowed.

various investors, with short sales allowed (portfolio allocations to asset classes were derived in our efficient frontier algorithm):

- Low-risk investor (as represented by 2.90 per cent standard deviation of portfolio return)

$17.47 \%$

$3.23 \%$

$3.99 \%$

$-3.28 \%$

$5.59 \%$

$8.79 \%$

$64.21 \%$
Social Security Participation

Large capitalisation stocks

Small capitalisation stocks

Corporate bonds

Long-term Treasury bonds

Medium-term Treasury notes

Treasury bills 
- Medium-risk investor (represented by 12.26 per cent standard deviation)

$35.64 \% \quad$ Social Security Participation

$32.16 \% \quad$ Large capitalisation stocks

$26.33 \% \quad$ Small capitalisation stocks

$-150.60 \% \quad$ Corporate bonds

$-16.90 \% \quad$ Long-term Treasury bonds

362.74\% Medium-term Treasury notes

$-189.37 \% \quad$ Treasury bills

and we find similar characteristics as for 12 per cent standard deviation, with high-risk investors, represented by 19.94 per cent standard deviation of optimal portfolio:

- High-risk investor (19.94 per cent standard deviation)

$\begin{aligned} 48.76 \% & \text { Social Security Participation } \\ 53.06 \% & \text { Large capitalisation stocks } \\ 42.46 \% & \text { Small capitalisation stocks } \\ -256.99 \% & \text { Corporate bonds } \\ -33.15 \% & \text { Long-term Treasury bonds } \\ 618.37 \% & \text { Medium-term Treasury notes } \\ -372.52 \% & \text { Treasury bills }\end{aligned}$

Although the last two portfolios may seem extreme and unrealistic, it is quite striking in that they suggest significant allocation to stocks and to Social Security, and a significant short position in corporate debt and short-term debt. Furthermore, the very large position in medium-term debt combined with the short position in short-term debt may seem unrealistic, but one can view this as a situation where a consumer invests in assets such as deferred annuities, GICs and stable value funds, which credit medium-term interest rates, while he or she borrows substantially.

Biggs and Springstead ${ }^{25}$ provided a thorough review of current and projected Social Security replacement rates (under alternative definitions, but generally referring to the ratio of post-retirement income derived from Social Security to pre-retirement income) and found them to vary between 29 and 42 per cent, with higher rates for low-income workers and lower for high-income workers generally. The portfolio allocations we find here, which would translate into similar levels of replacement rates, are lower for low-risk investors, but higher for investors willing to accept risk.

The key features in the medium- and high-risk portfolios allocations are very high level of borrowing with positive allocations in Social Security, stocks and medium-term Treasuries. It should be noted that medium-term Treasuries are commonly used as benchmarks for fixed deferred annuities, providing guarantees to the consumers, and income level similar to medium-term Treasury debt.

In the next two figures we compare efficient frontiers with and without Social Security Participation, first with short sales allowed, and then without short sales. This analysis shows us whether Social Security is a desired asset class for American investors, that is, whether it enhances the efficient frontier. Since the efficient frontier including Social Security lies above that without Social Security, there is such enhancement. We already knew that to be

\footnotetext{
${ }^{25}$ Biggs and Springstead (2008).
} 
the case, since the allocation to Social Security is positive in efficient portfolios, but these figures illustrate the degree to which this happens.

We see that the enhancement of the efficient frontier is relatively small and it expresses itself mostly in the reduction of risk. It seems that Social Security acts as a "conservative anchor" for portfolios of individual investors. With short sales allowed, this effect is less pronounced. This is important in view of the key question of this study: what is the effect of Social Security on the portfolios of American investors? While in the short run, one can hardly assume large short positions, unless one is an institutional investor, in the long run, short positions in bonds are taken on by assuming debt. Americans do carry large amounts of debt, and have a low savings rate. This may indeed be the way to assume short positions in debt called for in optimal portfolios (which tend to have between 15 per cent and 20 per cent in Social Security, with the rest in money-market instruments for low-risk investors or stocks for higher risk investors, and then a significant short position in long-term bonds for all but low-risk investors).

It should be noted that the portfolio enhancement offered by Social Security is significantly greater if no short sales are allowed, and, in that case, more so for low-risk investors. Since low-risk investors also tend to be poorer, and thus have less access to tools allowing for creating short positions, we can reasonably infer that the benefit of Social Security in a portfolio tends to be the greatest for poorer participants.

\section{Real returns}

One of the distinguishing characteristics of Social Security in comparison with marketable capital assets is the fact that Social Security benefits are indexed to inflation. While such protection against inflation risk is not perfect within Social Security, it is unique as, apart from Social Security, real (i.e. adjusted for inflation) annuities are almost non-existent in the United States. Because of that feature, comparison of real returns of Social Security Participation with real returns of other capital assets is in order. We now take a look at efficient frontiers on the real (inflation-adjusted) basis. Figure 7 shows the efficient frontier

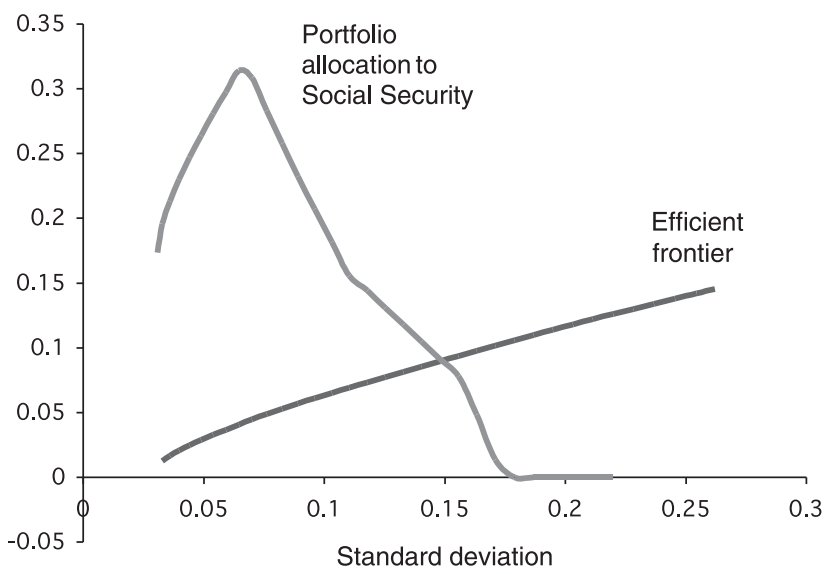

Figure 7. 1942-2010 efficient frontier and allocation to Social Security Participation, real returns, no short sales allowed. 


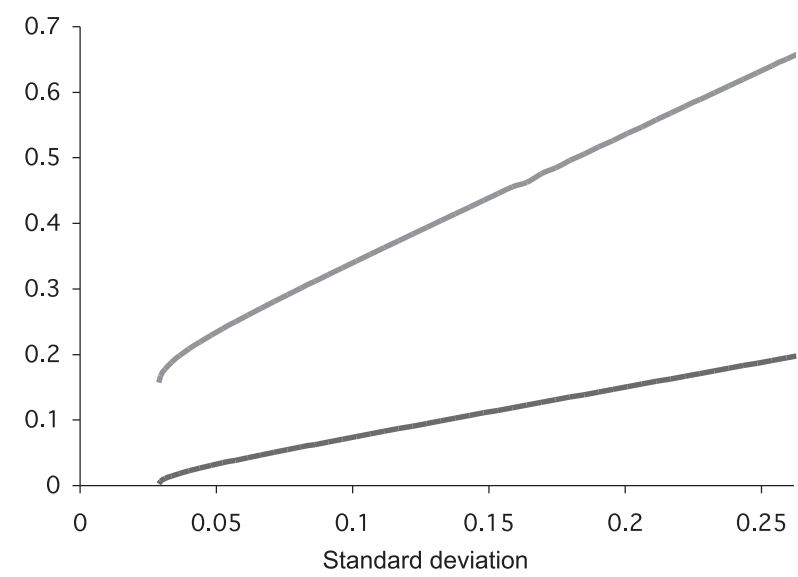

Figure 8. 1942-2010 efficient frontier and allocation to Social Security, short sales allowed, real returns.

and Social Security allocation with no short sales allowed based on real returns for 1942-2010, and Figure 8 shows the same with short sales allowed.

In Figure 8, the top curve shows portfolio allocation to Social Security Participation, while the bottom curve is the efficient frontier, showing the expected rate of return of a portfolio as a function of the standard deviation of the given portfolio. For both graphs, the independent variable is the standard deviation of the portfolio. We see that just as in the case of nominal rates of return, Social Security allocation actually increases with riskiness of the portfolio. In fact, at the level of standard deviation of 0.2008 , a good representation of high-risk investor, optimal portfolio consists of

\begin{aligned} & \hline $53.74 \%$ Social Security Participation \\ & $51.64 \%$ Large capitalisation stocks \\ & $43.78 \%$ Small capitalisation stocks \\ &$-268.33 \%$ Corporate bonds \\ &$-42.88 \%$ Long-term Treasury bonds \\ & $644.34 \%$ Medium-term Treasury notes \\ &$-382.27 \%$ Treasury bills \\ & \hline\end{aligned}

These values are actually very close to optimal allocation at this level of risk in a portfolio based on nominal rates of return, although optimal allocations based on real returns and nominal returns may vary, because of different sensitivities of rates of return of different asset classes to the inflation risk.

\section{Including real estate}

The portfolios analysed in this paper have not included an allocation to real estate, an important asset class in the portfolios of American investors. Home ownership is 
widespread in the United States and we can reasonably expect economic decisions of Americans to be affected by the rates of returns on the real estate they own. Furthermore, the recent credit crisis of 2008, and subsequent global economic downturn, were greatly influenced by the turmoil in the U.S. real estate market. However, real estate returns are not as widely available as capital markets data. We have made an effort to consider a real estate allocation by using the data published by National Council of Real Estate Investments Fiduciaries (NCREIF). ${ }^{26} \mathrm{We}$ included the national NPI index published by NCREIF as an alternative asset class serving as a proxy for real estate returns, and created an efficient frontier using both nominal and real returns. The inclusion of real estate resulted in lower optimal allocation to Social Security, especially for investors willing to tolerate higher levels of risk. The effect was more pronounced when real returns were considered.

Let us repeat our arbitrage argument: while investors do not have any choice as to whether they want to invest in the Social Security Participation, they are free to reallocate their marketable assets portfolio in response to the obligatory asset allocation to Social Security, and change their balance between work, education and leisure. Sub-optimal asset allocations with respect to portfolio choices available to them create arbitrage opportunities, which are likely to be exploited. This paper shows that these arbitrage opportunities may be quite dramatic, especially on the real basis with real estate included as an asset class. If real estate is included, real returns are considered, and short sales are allowed, portfolios assuming significant degree of risk hold large short positions in Social Security Participation. For example, for an investor willing to take on risk at the level of an annual standard deviation of 14.79 per cent, the optimal allocation is:

\begin{aligned} & \hline$-28.05 \%$ Social Security Participation \\ & $10.59 \%$ Large capitalisation stocks \\ & $42.60 \%$ Small capitalisation stocks \\ &$-92.69 \%$ Corporate bonds \\ &$-53.93 \%$ Long-term Treasury bonds \\ & $375.99 \%$ Medium-term Treasury notes \\ &$-308.09 \%$ Treasury bills \\ &$-153.56 \%$ Real estate \\ & \hline\end{aligned}

One could of course ask: can an individual investor short Social Security? Indeed, there is no direct mechanism for such a transaction. But indirectly, this can be done by assuming a lot of debt implicitly secured by one's future wages and Social Security benefits. If the debt is paid in the future with Social Security benefits, while current investment is placed in risky securities, such as small capitalisation stocks, the effect is equivalent to shorting Social Security and buying stocks with proceeds. In the insurance literature, the phenomenon of the insured party assuming more risk because of insurance protection is termed moral hazard. Gokhale et $a l .{ }^{27}$ discuss the secular decline in the U.S. savings rate and point out the decline among the elderly, who receive the most benefits of risk protection from social insurance, as

\footnotetext{
${ }^{26}$ National Council of Real Estate Investments Fiduciaries (2011).

${ }^{27}$ Gokhale et al. (1996).
} 
the key factor. This study suggests that the relationship between Social Security and savings is more dynamic, incorporating the effects on the allocation of savings among investment choices, and optimal portfolio design.

\section{Conclusions}

Here is a summary of our key findings:

- Long-term real returns from Social Security should be probably expected to be in the range of about 1.86 per cent real, but possibly even lower (as low as 0.43 per cent) because of current economic circumstances and long-term financing shortfall of the system.

- Risk-averse consumers have an incentive to allocate a substantial portion of their portfolio to Social Security.

- Consumers willing to tolerate a high level of risk in their investment portfolios have a disincentive to participate in Social Security, and the system creates an arbitrage opportunity for them: to invest more aggressively, while borrowing and lowering their exposure to payroll taxes (e.g. by receiving income in the form of options).

There has been considerable debate regarding rates of return to Social Security participants that can be expected in the future. Estimates range from a low of 1 per cent real (although some claim that future generations will receive no benefits at all) to a high of 8 per cent real. This paper indicates that the returns are likely to be in the range of risk-free short-term government bonds. Given that Social Security is in fact as safe and secure as short-term government bonds (as it also provides inflation protection), this is not surprising. We believe that such information could be valuable to policy makers.

It also appears that Social Security acts as a "safe anchor" for the overall retirement investment portfolio of Americans, and hence its higher leverage and more aggressive investing. On the real return basis, if real estate is included in optimal portfolio, optimal portfolio allocation of very risk-averse investors (i.e. those investors who are only willing to accept low volatility of their portfolios) would include Social Security allocation, while investors willing to tolerate high level risk (again as measured by portfolio volatility) would actually prefer to short Social Security. Although this asset allocation may seem unrealistic at a first glance, policy implications of its optimality should not be underestimated. Risk-averse investors are steered away from investments in private markets, whereas risky investors have incentives for additional leverage and risk-taking. This divergence in risk attitudes may result in greater risk-premium accumulation to risky investors in the long run, and excessive concentration of risk in smaller groups of investors, possibly leading to increased systemic risk.

\section{Acknowledgements}

The author has received support for this research from the Committee for Knowledge Extension Research of the Society of Actuaries. 


\section{References}

Biggs, A.G. and Springstead, G.R. (2008) 'Alternate measures of replacement rates for social security benefits and retirement income', Social Security Bulletin 68(2): 1-19.

Chai, J., Maurer, R., Mitchell, O.S. and Rogalla, R. (2011) Lifecycle impacts of the financial and economic crisis on household optimal consumption, portfolio choice, and labor supply, National Bureau of Economic Research Working Paper No. 17134, Cambridge, MA: NBER.

Cook, T. and Hahn, T. (1989) 'The effect of changes in the federal funds rate target on market interest rates in the 1970s', Journal of Monetary Economics 24(3): 331-351.

Farnsworth, H. and Bass, R. (2003) 'The term structure with semi-credible targeting', Journal of Finance, American Finance Association 58(2): 839-866.

Geanakoplos, J., Mitchell, O.S. and Zeldes, S.P. (1998) Would a privatized social security system really pay a higher rate of return? National Bureau of Economic Research Working Paper 6713, Cambridge, MA: NBER.

Geanakoplos, J., Mitchell, O.S. and Zeldes, S.P. (1999) 'Social Security's Money's Worth', in O.S. Mitchell, R.J. Myers and H. Young (eds) Prospects for Social Security Reform, Philadelphia, PA: University of Pennsylvania Press, pp. 79-151.

Gokhale, J., Kotlikoff, L.J. and Sabelhaus, J. (1996) Understanding the postwar decline in national savings: A cohort analysis. National Bureau of Economic Research Working Paper No. 5571, Cambridge, MA: NBER.

Huang, C. and Litzenberger, R.H. (1988) Foundations for Financial Economics, Englewood Cliffs, NJ: Prentice-Hall.

Ibbotson Associates (2011) Ibbotson SBBI 2011 Classic Yearbook: Market Results for Stocks, Bonds, Bills and Inflation 1926-2010, Chicago, IL: Morningstar.

Keyfitz, N. and Beekman, J.A. (1984) Demography through Problems, New York: Springer-Verlag.

Krugman, P.R. (1991) 'Target zones and exchange rate dynamics', The Quarterly Journal of Economics 106(3): 669-682.

Leimer, D. (1994) Cohort specific measures of lifetime net social security transfers, ORS Working Paper No. 59, Office of Research and Statistics, Social Security Administration.

Lintner, J. (1965) 'The valuation of risk assets and the selection of risky investments in stock portfolios and capital budgets', The Review of Economics and Statistics 47(1): 13-37.

MacMinn, R.D. (1984) 'A general diversification theorem; A note', The Journal of Finance 39(2): 541-550.

Markowitz, H. (1952) 'Portfolio selection', Journal of Finance 7(1): 77-91.

Mossin, J. (1966) 'Equilibrium in a capital asset market', Econometrica 34(4): 769-783.

Mueller, J. (1997) The economics of pay-as-you-go social security and the economic cost of ending it: A report for the National Committee to Preserve Social Security and Medicare, Washington, DC.

Mueller, J. (1999) Winners and losers from "privatizing" social security: A report commissioned by the National Committee to Preserve Social Security and Medicare, Washington, DC.

Myers, R.J. and Schobel, B. (1992) 'An updated money's-worth analysis of social security retirement benefits', Transactions of the Society of Actuaries 44: 247-287.

National Council of Real Estate Investments Fiduciaries (2011) Indices data available at the website: www.ncreif. com/indices/, accessed 23 July 2011

Palacios, R. and Whitehouse, E. (1998) 'The role of choice in the transition to a funded pension system', World Bank Social Protection Division, p. 5.

Panjer, H. (ed.) (1998) Financial Economics with Applications, Schaumburg, IL: The Actuarial Foundation.

Richardson, D.P. and Seligman, J.S. (2005) 'Optimal retirement portfolios: Social security personal accounts in the context of the four pillars', The Geneva Papers on Risk and Insurance-Issues and Practice 30(4): 565-580.

Ross, S.A. (1976) 'Return, Risk and Arbitrage', in I. Friend and J. Bicksler (eds) Risk and Return in Finance, Cambridge, MA: Ballinger.

Samuelson, P. (1958) 'An exact consumption-loan model of interest with or without the social contrivance of money', Journal of Political Economy 66(6): 467-482.

Sharpe, W. (1964) 'Capital asset prices: A theory of market equilibrium under conditions of risk', The Journal of Finance 19(3): 425-442.

Smetters, K.A. and Chen, Y. (2010) Optimal portfolio choice over the life cycle with social security, The Pension Research Council, Working Paper No. 2010-06, The Wharton School, University of Pennsylvania, $w w w$. pensionresearchcouncil.org/publications/document.php?file=857, accessed 1 June 2013. 
696

Social Security Administration (1997) Report of the 1994-1996 Advisory Council on Social Security.

Social Security Administration (2011) 2011 Annual Report of the Board of Trustees of the Federal Old-Age and Survivors Insurance and Disability Insurance Trust Funds, from www.ssa.gov/oact/trsum/index.html, accessed 26 July 2011.

Timmins, N. (1998) 'The biggest question in town: America faces critical choices over the future of its most popular spending program', Financial Times, 20 March, p. 23.

Treynor, J.L. (1962) 'Toward a Theory of Market Value of Risky Assets', unpublished manuscript. A final version was published in 1999, in R.A. Korajczyk (ed.) Asset Pricing and Portfolio Performance: Models, Strategy and Performance Metrics, London: Risk Books, pp. 15-22. 


\section{Appendix A}

Table A1 Nominal returns

\begin{tabular}{|c|c|c|c|c|c|c|c|}
\hline Year & $\begin{array}{c}\text { Social } \\
\text { security } \\
\text { return (\%) }\end{array}$ & $\begin{array}{c}\text { Large cap } \\
\text { total return } \\
(\%)\end{array}$ & $\begin{array}{c}\text { Small cap } \\
\text { total return } \\
(\%)\end{array}$ & $\begin{array}{l}\text { Corporate bond } \\
\text { total return }(\%)\end{array}$ & $\begin{array}{c}\text { Long } T \text {-bond } \\
\text { total return } \\
(\%)\end{array}$ & $\begin{array}{c}\text { Intermediate } \\
\text { T-note total } \\
\text { return }(\%)\end{array}$ & $\begin{array}{l}\text { T-bill total } \\
\text { return }(\%)\end{array}$ \\
\hline 1938 & -53.48 & 31.12 & 32.80 & 6.13 & 5.53 & 6.23 & -0.02 \\
\hline 1939 & 54.38 & -0.41 & 0.35 & 3.97 & 5.94 & 4.52 & 0.02 \\
\hline 1940 & -40.48 & -9.78 & -5.16 & 3.39 & 6.09 & 2.96 & 0.00 \\
\hline 1941 & 125.52 & -11.59 & -9.00 & 2.73 & 0.93 & 0.50 & 0.06 \\
\hline 1942 & 26.15 & 20.34 & 44.51 & 2.60 & 3.22 & 1.94 & 0.27 \\
\hline 1943 & 20.29 & 25.90 & 88.37 & 2.83 & 2.08 & 2.81 & 0.35 \\
\hline 1944 & 5.26 & 19.75 & 53.72 & 4.73 & 2.81 & 1.80 & 0.33 \\
\hline 1945 & -0.24 & 36.44 & 73.61 & 4.08 & 10.73 & 2.22 & 0.33 \\
\hline 1946 & 1.80 & -8.07 & -11.63 & 1.72 & -0.10 & 1.00 & 0.35 \\
\hline 1947 & 18.89 & 5.71 & 0.92 & -2.34 & -2.62 & 0.91 & 0.50 \\
\hline 1948 & 14.23 & 5.50 & -2.11 & 4.14 & 3.40 & 1.85 & 0.81 \\
\hline 1949 & -7.86 & 18.79 & 19.75 & 3.31 & 6.45 & 2.32 & 1.10 \\
\hline 1950 & 1.35 & 31.71 & 38.75 & 2.12 & 0.06 & 0.70 & 1.20 \\
\hline 1951 & 22.25 & 24.02 & 7.80 & -2.69 & -3.93 & 0.36 & 1.49 \\
\hline 1952 & 11.43 & 18.37 & 3.03 & 3.52 & 1.16 & 1.63 & 1.66 \\
\hline 1953 & 4.64 & -0.99 & -6.49 & 3.41 & 3.64 & 3.23 & 1.82 \\
\hline 1954 & -7.49 & 52.62 & 60.58 & 5.39 & 7.19 & 2.68 & 0.86 \\
\hline 1955 & -5.80 & 31.56 & 20.44 & 0.48 & -1.29 & -0.65 & 1.57 \\
\hline 1956 & 15.16 & 6.56 & 4.28 & -6.81 & -5.59 & -0.42 & 2.46 \\
\hline 1957 & 0.11 & -10.78 & 14.57 & 8.71 & 7.46 & 7.84 & 3.14 \\
\hline 1958 & 9.97 & 43.36 & 64.89 & -2.22 & -6.09 & -1.29 & 1.54 \\
\hline 1959 & -13.35 & 11.96 & 16.40 & -0.97 & -2.26 & -0.39 & 2.95 \\
\hline 1960 & 13.85 & 0.47 & -3.29 & 9.07 & 13.78 & 11.76 & 2.66 \\
\hline 1961 & 6.40 & 26.89 & 32.09 & 4.82 & 0.97 & 1.85 & 2.13 \\
\hline 1962 & 6.72 & -8.73 & -11.90 & 7.95 & 6.89 & 5.56 & 2.73 \\
\hline 1963 & 5.47 & 22.80 & 23.57 & 2.19 & 1.21 & 1.64 & 3.12 \\
\hline 1964 & 12.09 & 16.48 & 23.52 & 4.77 & 3.51 & 4.04 & 3.54 \\
\hline 1965 & 2.94 & 12.45 & 41.75 & -0.46 & 0.71 & 1.02 & 3.93 \\
\hline 1966 & -7.54 & -10.06 & -7.01 & 0.20 & 3.65 & 4.69 & 4.76 \\
\hline 1967 & 17.45 & 23.98 & 83.57 & -4.95 & -9.18 & 1.01 & 4.21 \\
\hline 1968 & -3.41 & 11.06 & 35.97 & 2.57 & -0.26 & 4.54 & 5.21 \\
\hline 1969 & 13.60 & -8.50 & -25.05 & -8.09 & -5.07 & -0.74 & 6.58 \\
\hline 1970 & 11.89 & 4.01 & -17.43 & 18.37 & 12.11 & 16.86 & 6.52 \\
\hline 1971 & 6.54 & 14.31 & 16.50 & 11.01 & 13.23 & 8.72 & 4.39 \\
\hline 1972 & 5.88 & 18.98 & 4.43 & 7.26 & 5.69 & 5.16 & 3.84 \\
\hline 1973 & 1.15 & -14.66 & -30.90 & 1.14 & -1.11 & 4.61 & 6.93 \\
\hline 1974 & -3.82 & -26.47 & -19.95 & -3.06 & 4.35 & 5.69 & 8.00 \\
\hline 1975 & 9.54 & 37.20 & 52.82 & 14.64 & 9.20 & 7.83 & 5.80 \\
\hline 1976 & 9.18 & 23.84 & 57.38 & 18.65 & 16.75 & 12.87 & 5.08 \\
\hline 1977 & 7.27 & -7.18 & 25.38 & 1.71 & -0.69 & 1.41 & 5.12 \\
\hline 1978 & 6.14 & 6.56 & 23.46 & -0.07 & -1.18 & 3.49 & 7.18 \\
\hline 1979 & -3.52 & 18.44 & 43.46 & -4.18 & -1.23 & 4.09 & 10.38 \\
\hline 1980 & 14.25 & 32.42 & 39.88 & -2.76 & -3.95 & 3.91 & 11.24 \\
\hline 1981 & 8.37 & -4.91 & 13.88 & -1.24 & 1.86 & 9.45 & 14.71 \\
\hline 1982 & -4.62 & 21.41 & 28.01 & 42.56 & 40.36 & 29.10 & 10.54 \\
\hline
\end{tabular}


The Geneva Papers on Risk and Insurance-Issues and Practice

698

Table A1 (continued)

\begin{tabular}{|c|c|c|c|c|c|c|c|}
\hline Year & $\begin{array}{c}\text { Social } \\
\text { security } \\
\text { return (\%) }\end{array}$ & $\begin{array}{c}\text { Large cap } \\
\text { total return } \\
(\%)\end{array}$ & $\begin{array}{c}\text { Small cap } \\
\text { total return } \\
(\%)\end{array}$ & $\begin{array}{l}\text { Corporate bond } \\
\text { total return }(\%)\end{array}$ & $\begin{array}{c}\text { Long T-bond } \\
\text { total return } \\
(\%)\end{array}$ & $\begin{array}{c}\text { Intermediate } \\
\text { T-note total } \\
\text { return }(\%)\end{array}$ & $\begin{array}{l}\text { T-bill total } \\
\text { return }(\%)\end{array}$ \\
\hline 1983 & 14.23 & 22.51 & 39.67 & 6.26 & 0.65 & 7.41 & 8.80 \\
\hline 1984 & 5.26 & 6.27 & -6.67 & 16.86 & 15.48 & 14.02 & 9.85 \\
\hline 1985 & 8.05 & 32.16 & 24.66 & 30.09 & 30.97 & 20.33 & 7.72 \\
\hline 1986 & 2.36 & 18.47 & 6.85 & 19.85 & 24.53 & 15.14 & 6.16 \\
\hline 1987 & 8.44 & 5.23 & -9.30 & -0.27 & -2.71 & 2.90 & 5.47 \\
\hline 1988 & 9.52 & 16.81 & 22.87 & 10.70 & 9.67 & 6.10 & 6.35 \\
\hline 1989 & 6.90 & 31.49 & 10.18 & 16.23 & 18.11 & 13.29 & 8.37 \\
\hline 1990 & 3.63 & -3.17 & -21.56 & 6.78 & 6.18 & 9.73 & 7.81 \\
\hline 1991 & 3.71 & 30.55 & 44.63 & 19.89 & 19.30 & 15.46 & 5.60 \\
\hline 1992 & 4.97 & 7.67 & 23.35 & 9.39 & 8.05 & 7.19 & 3.51 \\
\hline 1993 & 0.86 & 9.99 & 20.98 & 13.19 & 18.24 & 11.24 & 2.90 \\
\hline 1994 & -1.20 & 1.31 & 3.11 & -5.76 & -7.77 & -5.14 & 3.90 \\
\hline 1995 & 6.90 & 37.43 & 34.46 & 27.20 & 31.67 & 16.80 & 5.60 \\
\hline 1996 & 7.99 & 23.07 & 17.62 & 1.40 & -0.93 & 2.10 & 5.21 \\
\hline 1997 & 10.13 & 33.36 & 22.78 & 12.95 & 15.85 & 8.38 & 5.26 \\
\hline 1998 & 7.00 & 28.58 & -7.31 & 10.76 & 13.06 & 10.21 & 4.86 \\
\hline 1999 & 6.38 & 21.04 & 29.79 & -7.45 & -8.96 & -1.77 & 4.68 \\
\hline 2000 & 7.91 & -9.11 & -3.59 & 12.87 & 21.48 & 5.83 & 3.39 \\
\hline 2001 & 2.49 & -11.88 & 22.77 & 10.65 & 3.70 & 7.62 & 3.83 \\
\hline 2002 & -0.36 & -22.10 & -13.28 & 16.33 & 17.84 & 12.98 & 1.65 \\
\hline 2003 & 0.73 & 28.70 & 60.70 & 5.27 & 1.45 & 2.40 & 1.02 \\
\hline 2004 & 7.87 & 10.87 & 18.39 & 8.72 & 8.51 & 2.25 & 1.20 \\
\hline 2005 & 8.03 & 4.91 & 5.69 & 5.87 & 7.81 & 1.36 & 2.98 \\
\hline 2006 & 6.41 & 15.80 & 16.17 & 3.24 & 1.19 & 3.14 & 4.80 \\
\hline 2007 & 1.35 & 5.49 & -5.22 & 2.60 & 9.88 & 10.05 & 4.66 \\
\hline 2008 & 0.75 & -37.00 & -36.72 & 8.78 & 25.87 & 13.11 & 1.60 \\
\hline 2009 & -5.56 & 26.46 & 28.09 & 3.02 & -14.90 & -2.40 & 0.10 \\
\hline 2010 & -3.02 & 15.06 & 31.26 & 12.44 & 10.14 & 7.12 & 0.12 \\
\hline
\end{tabular}




\section{Appendix B}

Table B1 Real returns

\begin{tabular}{|c|c|c|c|c|c|c|c|}
\hline Year & $\begin{array}{c}\text { Social } \\
\text { security real } \\
\text { return }(\%)\end{array}$ & $\begin{array}{l}\text { Large cap } \\
\text { total real } \\
\text { return }(\%)\end{array}$ & $\begin{array}{l}\text { Small cap } \\
\text { total real } \\
\text { return }(\%)\end{array}$ & $\begin{array}{c}\text { Long corporate } \\
\text { total real } \\
\text { return }(\%)\end{array}$ & $\begin{array}{l}\text { Long } T \text {-bond } \\
\text { total real } \\
\text { return }(\%)\end{array}$ & $\begin{array}{c}\text { Intermediate } \\
\text { T-note total real } \\
\text { return }(\%)\end{array}$ & $\begin{array}{l}\text { T-bill total } \\
\text { real return } \\
\quad(\%)\end{array}$ \\
\hline 1938 & -52.15 & 34.87 & 36.60 & 9.16 & 8.55 & 9.27 & 2.84 \\
\hline 1939 & 55.12 & 0.07 & 0.83 & 4.47 & 6.45 & 5.02 & 0.50 \\
\hline 1940 & -41.04 & -10.64 & -6.06 & 2.41 & 5.08 & 1.98 & -0.95 \\
\hline 1941 & 105.54 & -19.42 & -17.06 & -6.37 & -8.01 & -8.40 & -8.80 \\
\hline 1942 & 15.43 & 10.11 & 32.23 & -6.12 & -5.55 & -6.73 & -8.25 \\
\hline 1943 & 16.60 & 22.04 & 82.60 & -0.32 & -1.05 & -0.34 & -2.72 \\
\hline 1944 & 3.09 & 17.28 & 50.54 & 2.57 & 0.69 & -0.30 & -1.74 \\
\hline 1945 & -2.44 & 33.44 & 69.79 & 1.79 & 8.29 & -0.03 & -1.88 \\
\hline 1946 & -13.85 & -22.20 & -25.21 & -13.91 & -15.45 & -14.52 & -15.07 \\
\hline 1947 & 9.06 & -3.03 & -7.42 & -10.41 & -10.67 & -7.43 & -7.81 \\
\hline 1948 & 11.22 & 2.72 & -4.69 & 1.39 & 0.67 & -0.84 & -1.85 \\
\hline 1949 & -6.17 & 20.97 & 21.95 & 5.20 & 8.40 & 4.20 & 2.95 \\
\hline 1950 & -4.20 & 24.50 & 31.16 & -3.47 & -5.42 & -4.81 & -4.34 \\
\hline 1951 & 15.47 & 17.14 & 1.82 & -8.09 & -9.26 & -5.20 & -4.14 \\
\hline 1952 & 10.46 & 17.34 & 2.13 & 2.62 & 0.28 & 0.74 & 0.77 \\
\hline 1953 & 3.99 & -1.60 & -7.07 & 2.77 & 3.00 & 2.59 & 1.19 \\
\hline 1954 & -7.03 & 53.39 & 61.39 & 5.92 & 7.73 & 3.20 & 1.37 \\
\hline 1955 & -6.15 & 31.08 & 20.00 & 0.11 & -1.65 & -1.02 & 1.20 \\
\hline 1956 & 11.95 & 3.60 & 1.38 & -9.40 & -8.22 & -3.19 & -0.39 \\
\hline 1957 & 9.32 & -13.40 & 11.21 & 5.52 & 4.31 & 4.68 & 0.12 \\
\hline 1958 & 8.07 & 40.88 & 62.04 & -3.91 & -7.71 & -3.00 & -0.22 \\
\hline 1959 & -15.68 & 10.31 & 14.68 & -2.43 & -3.70 & -1.86 & 1.43 \\
\hline 1960 & 10.15 & -1.00 & -4.70 & 7.48 & 12.12 & 10.13 & 1.16 \\
\hline 1961 & 5.69 & 26.05 & 31.21 & 4.12 & 0.30 & 1.17 & 1.45 \\
\hline 1962 & 5.05 & -9.83 & -12.96 & 6.65 & 5.60 & 4.29 & 1.49 \\
\hline 1963 & 2.53 & 20.81 & 21.56 & 0.53 & -0.43 & -0.01 & 1.45 \\
\hline 1964 & 10.77 & 15.11 & 22.07 & 3.54 & 2.29 & 2.82 & 2.32 \\
\hline 1965 & 1.00 & 10.33 & 39.08 & -2.34 & -1.19 & -0.88 & 1.97 \\
\hline 1966 & -8.38 & -12.98 & -10.02 & -3.05 & 0.29 & 1.30 & 1.36 \\
\hline 1967 & 13.84 & 20.32 & 78.15 & -7.75 & -11.86 & -1.97 & 1.14 \\
\hline 1968 & -4.05 & 6.05 & 29.84 & -2.05 & -4.76 & -0.17 & 0.47 \\
\hline 1969 & 5.62 & -13.77 & -29.37 & -13.38 & -10.54 & -6.46 & 0.44 \\
\hline 1970 & 8.24 & -1.40 & -21.73 & 12.21 & 6.28 & 10.78 & 0.98 \\
\hline 1971 & 1.74 & 10.59 & 12.71 & 7.40 & 9.55 & 5.19 & 1.00 \\
\hline 1972 & 2.38 & 15.06 & 0.99 & 3.72 & 2.20 & 1.69 & 0.42 \\
\hline 1973 & -7.68 & -21.56 & -36.49 & -7.04 & -9.11 & -3.85 & -1.72 \\
\hline 1974 & -14.01 & -34.47 & -28.65 & -13.60 & -7.00 & -5.80 & -3.74 \\
\hline 1975 & 2.36 & 28.21 & 42.81 & 7.13 & 2.05 & 0.77 & -1.13 \\
\hline 1976 & 4.17 & 18.16 & 50.16 & 13.20 & 11.39 & 7.69 & 0.26 \\
\hline 1977 & 0.46 & -13.07 & 17.43 & -4.74 & -6.99 & -5.02 & -1.55 \\
\hline 1978 & 1.64 & -2.27 & 13.23 & -8.35 & -9.36 & -5.08 & -1.70 \\
\hline 1979 & -15.43 & 4.53 & 26.61 & -15.44 & -12.83 & -8.14 & -2.59 \\
\hline 1980 & -2.62 & 17.81 & 24.45 & -13.49 & -14.55 & -7.55 & -1.03 \\
\hline 1981 & -0.52 & -12.71 & 4.53 & -9.34 & -6.50 & 0.47 & 5.30 \\
\hline 1982 & -4.78 & 16.89 & 23.24 & 37.25 & 35.13 & 24.29 & 6.42 \\
\hline
\end{tabular}


The Geneva Papers on Risk and Insurance-Issues and Practice

700

Table B1 (continued)

\begin{tabular}{|c|c|c|c|c|c|c|c|}
\hline Year & $\begin{array}{c}\text { Social } \\
\text { security real } \\
\text { return }(\%)\end{array}$ & $\begin{array}{l}\text { Large cap } \\
\text { total real } \\
\text { return }(\%)\end{array}$ & $\begin{array}{l}\text { Small cap } \\
\text { total real } \\
\text { return }(\%)\end{array}$ & $\begin{array}{c}\text { Long corporate } \\
\text { total real } \\
\text { return }(\%)\end{array}$ & $\begin{array}{l}\text { Long } T \text {-bond } \\
\text { total real } \\
\text { return }(\%)\end{array}$ & $\begin{array}{c}\text { Intermediate } \\
T \text {-note total real } \\
\text { return }(\%)\end{array}$ & $\begin{array}{l}T \text {-bill total } \\
\text { real return } \\
\quad(\%)\end{array}$ \\
\hline 1983 & 5.44 & 18.03 & 34.56 & 2.37 & -3.03 & 3.48 & 4.82 \\
\hline 1984 & -1.85 & 2.23 & -10.22 & 12.42 & 11.09 & 9.69 & 5.68 \\
\hline 1985 & 4.13 & 27.36 & 20.13 & 25.36 & 26.21 & 15.96 & 3.81 \\
\hline 1986 & 1.22 & 17.15 & 5.66 & 18.51 & 23.14 & 13.85 & 4.97 \\
\hline 1987 & 3.86 & 0.79 & -13.13 & -4.48 & -6.82 & -1.45 & 1.02 \\
\hline 1988 & 4.85 & 11.87 & 17.67 & 6.01 & 5.03 & 1.61 & 1.85 \\
\hline 1989 & 2.15 & 25.65 & 5.28 & 11.07 & 12.86 & 8.26 & 3.55 \\
\hline 1990 & -1.33 & -8.75 & -26.08 & 0.63 & 0.07 & 3.41 & 1.60 \\
\hline 1991 & 0.63 & 26.67 & 40.34 & 16.33 & 15.76 & 12.03 & 2.46 \\
\hline 1992 & 2.01 & 4.64 & 19.87 & 6.31 & 5.00 & 4.17 & 0.59 \\
\hline 1993 & -1.84 & 7.05 & 17.74 & 10.16 & 15.08 & 8.26 & 0.15 \\
\hline 1994 & 2.45 & -1.32 & 0.43 & -8.21 & -10.17 & -7.61 & 1.20 \\
\hline 1995 & 4.25 & 34.03 & 31.13 & 24.05 & 28.41 & 13.91 & 2.98 \\
\hline 1996 & 4.52 & 19.12 & 13.84 & -1.86 & -4.11 & -1.18 & 1.83 \\
\hline 1997 & 6.47 & 31.13 & 20.73 & 11.06 & 13.91 & 6.57 & 3.50 \\
\hline 1998 & 5.30 & 26.54 & -8.78 & 9.01 & 11.27 & 8.46 & 3.20 \\
\hline 1999 & 3.60 & 17.89 & 26.40 & -9.87 & -11.34 & -4.33 & 1.95 \\
\hline 2000 & 5.35 & -12.09 & -6.75 & 9.17 & 17.50 & 2.36 & 0.00 \\
\hline 2001 & 0.92 & -13.23 & 20.88 & 8.95 & 2.11 & 5.97 & 2.24 \\
\hline 2002 & -2.68 & -23.91 & -15.30 & 13.63 & 15.10 & 10.35 & -0.71 \\
\hline 2003 & -1.13 & 26.33 & 57.73 & 3.33 & -0.42 & 0.51 & -0.84 \\
\hline 2004 & 4.46 & 7.37 & 14.65 & 5.29 & 5.08 & -0.98 & -1.99 \\
\hline 2005 & 4.46 & 1.44 & 2.19 & 2.37 & 4.24 & -1.99 & -0.43 \\
\hline 2006 & 3.77 & 12.93 & 13.29 & 0.68 & -1.32 & 0.59 & 2.20 \\
\hline 2007 & -2.62 & 1.35 & -8.94 & -1.42 & 5.57 & 5.74 & 0.56 \\
\hline 2008 & 0.65 & -37.06 & -36.78 & 8.68 & 25.76 & 13.01 & 1.51 \\
\hline 2009 & -8.07 & 23.11 & 24.70 & 0.29 & -17.15 & -4.99 & -2.55 \\
\hline 2010 & -4.45 & 13.36 & 29.33 & 10.78 & 8.52 & 5.54 & -1.36 \\
\hline
\end{tabular}

\section{About the Author}

Krzysztof Ostaszewski is a professor of Mathematics and Actuarial Program Director at Illinois State University, and Research Director for Life Insurance and Pensions at The Geneva Association. He holds a Ph.D. in Mathematics from the University of Washington, is a Fellow of the Society of Actuaries, Fellow of the Singapore Actuarial Society, Chartered Enterprise Risk Analyst, Chartered Financial Analyst and a member of the American Academy of Actuaries. 